\title{
LA IMPORTANCIA DE LA EMPRESA FAMILIAR Y \\ LA INSUFICIENTE REGULACIÓN URBANA DE LA MICROEMPRESA FAMILIAR
}

\author{
THE IMPORTANCE OF THE FAMILY BUSINESS AND THE \\ INSUFFICIENT URBAN REGULATION OF THE FAMILY \\ MICRO-BUSINESS
}

ALFREDO FERRANTE*

Profesor de Derecho Civil Universidad Alberto Hurtado

Santiago - Chile

\section{RESUMEN}

La actual regulación de la microempresa familiar asocia el negocio familiar con un determinado contexto urbano: la vivienda. El artículo destaca que, sin embargo, esto no es suficiente para resaltar la importancia de la empresa familiar, la cual carece de una adecuada ordenación en el panorama jurídico chileno. Mediante una investigación y metodología propia de la ciencia jurídica, después de haber aislado sus problemáticas, se aboga por una mejor y más apropiada regulación tanto de esta institución como de los derechos de los miembros que trabajan en ella.

Palabras claves: Familia, Vivienda, Microempresa familiar, Empresa familiar.

* Profesor de Derecho Civil en la Universidad Alberto Hurtado (Santiago De Chile). Doctor Europeo en Derecho Civil cum laude por la Universidad de Oviedo. Correo electrónico: aferrante@uahurtado.cl. Artículo recibido el 3 de agosto de 2018 y aceptado para su publicación el 7 de noviembre de 2018 . 


\section{ABSTRACT}

The current regulation of the Family Micro-companies, associates to the family business with a specific urban context: the house. The article emphasizes that, nevertheless, this is not enough to highlight the importance of the family business that has a low regulation in the Chilean legal landscape. Through research and methodology of legal science, after having highlighted these problems, it advocates a better and more appropriate regulation of this institution and also of the rights of its members.

Keywords: Family, House, Family Micro-company, Family Enterprise.

\section{INTRODUCCIÓN Y PRESENTACIÓN}

Los ambientes urbanos y en particular la vivienda y el hábitat residencial asumen un interés relevante no sólo desde una perspectiva arquitectónica y social sino también una jurídico-económica: en particular, la que se refleja en la microempresa familiar. Conscientes de su regulación particular (Ley 19.749 de 2001), se aboga por la necesidad de reflexionar sobre una reglamentación más amplia y completa, dada la importancia que la empresa familiar tiene en cualquier sistema socioeconómico. El objetivo de estas páginas es destacar la necesidad de una apropiada normativa para esta verdadera institución jurídica y social en el actual panorama legislativo y para dar autonomía a esta empresa más allá de su contexto, íntimamente relacionado con el ambiente urbano, la vivienda.

Efectivamente, la empresa familiar resulta una forma de organización camaleónica y multidisciplinaria, que afecta aspectos de derecho civil y mercantil, pero también tributario, laboral y urbanístico, con repercusiones en el plano de la seguridad social. Pese a la relevancia de estos aspectos, la doctrina jurídica no los ha abordado con profundidad, ${ }^{1}$ aumentando su principal problemática, cual es, que la empresa familiar, genéricamente considerada, no tiene una ordenación apropiada en Chile.

\footnotetext{
${ }^{1}$ Una oportuna addenda se hace necesaria en esta ocasión: debe darse constancia de que recientemente la doctrina se ha ocupado de profundizar algunos aspectos. En particular interesantísimo el estudio que se dedica a proponer determinados instrumentos que faciliten la conservación de la empresa familiar. A estos efectos se reenvía al trabajo de BARRIA PAREDEs, Manuel, "La empresa familiar o explotación agropecuaria: mecanismos que permitan su continuidad a la muerte de su titular a la luz del derecho sucesorio chileno", Revista Chilena de Derecho Privado, 2018, nº 31 (en prensa).
} 
La metodología del presente trabajo es la propia de las ciencias jurídicas y utiliza como base de análisis la legislación positiva, recurriendo a los procedimientos propios de la dogmática; es decir, el examen razonado del derecho y los pronunciamientos de los tribunales ordinarios y administrativos, utilizándose también material doctrinario nacional y extranjero, para contraponer el estudio de esta reglamentación en otros ordenamientos.

\section{PERMEABILIDAD DE LOS CONCEPTOS DE FAMILIA Y EMPRESA}

En ciertas ocasiones, en lugar de definir técnicamente una institución jurídica se prefiere la elaboración de un concepto. Esto se debe a la imposibilidad de determinarla con suficiente precisión o a que la importancia del mismo instituto es tan relevante que sobraría una consagración explícita.

Al tratar la empresa familiar se entremezclan dos términos, el de "empresa" y el de "familia", los que, aparentemente, escapan a cualquier aspecto definitorio o que resultan de difícil identificación.

Así, la familia, claro pilar socio jurídico, si bien es "el núcleo fundamental de la sociedad" y asume un valor y tutela constitucional en el primer artículo de la Constitución Política, no se encuentra definida con propiedad. Aún más, resulta curioso que ahí donde esto ocurre, se asume una definición suis generis proporcionada por el Código Civil. ${ }^{2}$

Efectivamente, ésta no sólo queda delimitada a un determinado contexto, el llamado "derecho de habitación", sino que, al incluir a "los sirvientes", trasciende los vínculos sanguíneos (vid. art. 815 CC). ${ }^{3}$ Además, se evidencia otra particularidad, que es su anclaje con un vínculo laboral específico, ${ }^{4}$ es decir, el del trabajo doméstico. Lo anterior es aún más patente si se piensa que al hogar en el cual se desempeña un trabajador de casa particular no

\footnotetext{
${ }^{2}$ Art. 815 CC: “(omissis) La familia comprende al cónyuge y los hijos; tanto los que existen al momento de la constitución, como los que sobrevienen después, y esto aun cuando el usuario o el habitador no esté casado, ni haya reconocido hijo alguno a la fecha de la constitución.

Comprende asimismo el número de sirvientes necesarios para la familia".

Comprende, además, las personas que a la misma fecha vivían con el habitador o usuario y a costa de éstos; y las personas a quienes éstos deben alimentos".

${ }^{3}$ CC: Código Civil, DL: Decreto Legislativo; Ord.: Ordenanza CGR: Contraloría General de la República; DT: Dirección del Trabajo, Minvu: Ministerio de Vivienda y Urbanismo. Los pronunciamientos citados de la Contraloría pueden consultarse en su página web.

${ }^{4}$ La Ord. D.T. N. 3750/0064 de 18 de julio de 2016 y el dictamen D.T. n. 1507/17 de 5 de abril de 2011 (de la Dirección del Trabajo) admiten que los empleadores de trabajadores de casa particular se asimilen al concepto de empresa al tenor del art. 3 del Código de Trabajo, para el sólo efecto de afiliarse a una Caja de Compensación de Asignación Familiar.
} 
procede calificarlo de empresa para los efectos de su adhesión a una caja de compensación de asignación familiar. ${ }^{5}$

Por otra parte, en caso de delitos o malos tratos asociados a la "familia", el legislador chileno amplía el concepto de "familiar", dirigiéndolo también a quienes no pueden definirse propiamente como tales (el ex cónyuge y "el padre del hijo común", art. 5 Ley 20.066). ${ }^{6}$

Desde una tercera perspectiva, debe constatarse que existe otro concepto de familia en el ordenamiento chileno y que se deduce de los arts. 28 y 30 CC. En este escenario, el "familiar" asume el sinónimo de "pariente". La familia se conforma en su línea vertical al infinito mediante el parentesco por consanguinidad en cualquiera de sus grados (art. $28 \mathrm{CC}$ ) y en un ámbito más restringido, respecto del parentesco por afinidad (art. 30 CC). Sin embargo, este concepto teórico y extremadamente ampliado encuentra una limitación de facto en las relaciones patrimoniales de sus miembros, ya que el patrimonio se ciñe a la personalidad y consecuentemente, en la práctica, se relaciona con las personas consideradas en vida; de ahí la justificación y la ratio del modo de adquirir sucesión por causa de muerte. Por ello, aunque no debe olvidarse la importancia de los negocios jurídicos mortis causa y que el difunto asume un rol preminente para el derecho sucesorio, sus efectos se materializan exclusivamente en aquellos familiares que sobreviven. ${ }^{7}$ Así, desde esta perspectiva, el concepto de familiar -y, por ende, de pariente- debe limitarse y circunscribirse a la finalidad de tutelar sólo a determinados sujetos para evitar que el patrimonio familiar se disgregue excesivamente.

Actualmente el legislador delimita el abanico de los miembros -parientes consanguíneos o afines- mediante tres grupos, relegándolo hasta un cierto grado, sea este, el tercero ( $v$.gr. arts. 965,969 CC, art. 5 Ley 20.066), el cuarto (v.gr. arts. 412, 443, 448, 462 CC) o el sexto (v.gr. art. 968, 992 CC).

${ }^{5}$ Conforme a la Ord. D.T. n. 1507/017 de 5 de abril de 2011.

${ }^{6}$ Art. 5 de la Ley $n^{\circ} 20.066$ sobre violencia intrafamiliar: "Violencia intrafamiliar. Será constitutivo de violencia intrafamiliar todo maltrato que afecte la vida o la integridad física o psíquica de quien tenga o haya tenido la calidad de cónyuge del ofensor o una relación de convivencia con él; o sea pariente por consanguinidad o por afinidad en toda la línea recta o en la colateral hasta el tercer grado inclusive, del ofensor o de su cónyuge o de su actual conviviente.

También habrá violencia intrafamiliar cuando la conducta referida en el inciso precedente ocurra entre los padres de un hijo común, o recaiga sobre persona menor de edad, adulto mayor o discapacitada que se encuentre bajo el cuidado o dependencia de cualquiera de los integrantes del grupo familiar."

${ }^{7}$ Esto queda, en parte, refrendado por el hecho de que el nasciturus llega a ser familiar exclusivamente a condición de que adquiera existencia jurídica mediante su nacimiento, aunque se entienda que sus derechos se retrotraen al momento de su concepción. 
Destacada la elasticidad del concepto de familia y familiar, una vez que nos centramos en el segundo elemento de referencia, esto es, la empresa, puede decirse lo mismo, ya que no tiene en la actualidad una definición jurídica.

Por cierto, no se encuentra definida en el Código de Comercio, pero, indirectamente y con elementos laborales, el art. 3 del Código de Trabajo ha dado bastante que pensar a la doctrina. ${ }^{8}$

En ésta, "se entiende por empresa toda organización de medios personales, materiales e inmateriales, ordenados bajo la dirección de un empleador, para el logro de fines económicos, sociales, culturales o benéficos, dotada de una individualidad legal determinada". Esta conceptualización se limita al ámbito laboral y específicamente, al del empleador. ${ }^{9}$

Hecha esta panorámica, debe asumirse que familia y empresa son dos conceptos que se caracterizan por su plasticidad y aspectos multidisciplinarios. Esta interdisciplinariedad ha conducido a proporcionar definiciones que finalmente no han sido apropiadas, por ejemplo, en el ámbito tributario, ${ }^{10} \mathrm{o}$ incluso a duplicar -en el derecho mercantil y civil- las definiciones jurídicas de empresario de transporte. ${ }^{11}$

Sin embargo, la imposibilidad de proporcionar un concepto omnicomprensivo o general tanto de empresa como de familia, no debe ser óbice para definir el particular escenario que se forma por la mixtura de ambos términos: la empresa familiar. La asunción de estos términos en conjunto permite identificar un determinado contexto de referencia, para defender una nueva normativa.

\section{EN BÚSQUEDA DEL MOLDE JURÍDICO DE LA EMPRESA FAMILIAR}

Indudablemente, esta tipología de actividad negocial debe estar sometida

\footnotetext{
${ }^{8}$ Palavecino, Claudio, "El concepto de empresa y su problemática", Revista Laboral Chilena, 2008, $\mathrm{n}^{\circ}$ 168, pp. 80-85; Fuenzalida Puelma, Sergio, "Concepto jurídico de empresa y su relación con otras figuras del derecho", R.D.J., 1967, T. LXIV, n. 3, p. 43-53, Ugarte Cataldo, José Luis, "El concepto legal de empresa y el derecho laboral: cómo salir del laberinto", Revista Chilena de Derecho Privado, 2013, n 20, pp. 185-213; ArteAga Echeverría, Ignacio, "En busca del concepto jurídico de empresa", Revista Chilena de Derecho, 2002, n 3, pp. 603-620.

${ }^{9}$ Efectivamente se considera que "los medios con que cuenta la empresa deben ordenarse bajo la dirección de un empleador". Ord. D.T. n 3406/054, de 3 de septiembre de 2014.

${ }^{10} \mathrm{La}$ referencia es a la definición de empresa a tenor del derogado art. 2, n 4 de la Ley 17.073 de 1968, que estableció un impuesto al patrimonio: cfr. Arteaga EcheVERría, cit. (n. 8), p. 604.

${ }^{11}$ Piénsese en la doble definición de empresario de transporte contenida en los arts. 166 del Código de Comercio y art. 2013 CC, respectivamente.
} 
a una reglamentación distintiva; otra cosa es que se predisponga una regulación ad hoc, considerando a la empresa familiar como una verdadera institución jurídica con estatuto propio.

Es este sentido pueden plantearse dos modelos, uno que respalda su regulación total e independiente y otro que, no pronunciándose expresamente, comporta la aplicación de normas propias de otros contextos empresariales tipificados.

Este último se da, con mayor razón, cuando los familiares son los que siguen detentando su propiedad o controlan una determinada empresa o sociedad. Esto presupone, por una parte, que se esté hablando de una actividad que ya tiene una estructura compleja y que esté bien organizada. Desde esta perspectiva, la "empresa", en ausencia de reglamentación ad hoc, puede revestir formas societarias como PYME o una sociedad civil o comercial o, incluso, una S.A., una S.R.L. y hasta una S.P.A. o consorcio empresarial cuyas cuotas pertenezcan, en la mayoría, a socios de una misma familia.

Al modelo que se acaba de plantear, se opone otro, en el cual es el ámbito familiar, y no el de la estructura empresarial, el que asume un papel clave. Se centra en que la gestión empresarial debe encuadrarse en el ámbito familiar, sin llegar a ser muy compleja. Y ve en su cabeza a una sola persona, que utiliza su vivienda como lugar de desarrollo de la actividad y que es coadyuvado por los demás miembros del grupo.

Los dos modelos parten de un presupuesto de familia totalmente diferente. Si el primero regula un núcleo más bien unido en el patrimonio, en el segundo, el familiar es un colaborador que juega un importante rol dentro de la empresa mediante sus capacidades decisionales y laborales, incluso prescindiendo de su patrimonio personal.

Ambos patrones se relacionan parcialmente entre sí, ya que una empresa familiar que aspire a consolidarse en las futuras generaciones tenderá a crecer y a alcanzar una estructura organizativa más compleja, muy probablemente externalizando algunos trabajos o incorporando miembros ajenos a los parientes en mayor proporción.

Si se opta por un modelo que haga de la empresa familiar una institución que prescinda de las otras estructuras típicas societarias, deberá evaluarse en qué medida se ponderan entre sí sus dos elementos formantes (empresa y familia) y también habrá que definir quién será el familiar de referencia.

Por lo anterior, al demarcar la envergadura de la empresa (que, recordemos, en este caso, no podría asumir una estructura ya tipificada por el ordenamiento), ésta podría calibrarse en relación con el número de miembros que pertenecen y trabajan en ella. 
La ventaja de utilizar ambos parámetros es intentar acotar con claridad a la empresa familiar. Sin embargo, esto podría conllevar la desventaja de encajarla en una estructura jurídica que eventualmente frenara su expansión económica. Por ejemplo, sería el caso en el cual se calificara como tal a una empresa que no supere un determinado monto de facturación anual o que no tenga más de un número predeterminado de sujetos. Por ello, si el parámetro relacionado a la limitación de grado de parentesco resulta necesario, el primero debiese ser facultativo, para evitar que se obstaculice o impida el desarrollo empresarial.

En definitiva, la empresa familiar podría encajarse en uno de dos paradigmas jurídicos; uno que defiende su expresa tipificación como instituto jurídico per se y otro que, consciente de la permeabilidad de los dos conceptos que la forman, deja un margen de acción más amplio y legitima ajustarla en otras estructuras societarias o empresariales tipificadas. Este último aspecto toma relevancia si se piensa que la empresa familiar podría interaccionar también con la empresa individual de responsabilidad limitada, creada por la Ley $19.857 / 2003 .^{12}$

\section{LA ELECCIÓN CHILENA: LAASOCIACIÓN AL MODELOURBANÍSTICO DE LA CASA HABITACIÓN}

Los dos modelos planteados, aunque contrapuestos, podrían ser compatibles en algunos casos; más, si se asumieran diversas categorías o subcategorías de empresa familiar.

Esto es lo que ocurre en el ordenamiento chileno, que opta por disciplinar sólo una tipología, la que define la "microempresa familiar", introducida por la Ley 19.749 de $2001^{13}$ y su reglamento, ${ }^{14}$ incorporando su definición en la Ley de Rentas Municipales. ${ }^{15}$

\footnotetext{
${ }^{12} \mathrm{La}$ empresa individual de responsabilidad limitada se crea por la Ley $\mathrm{N}^{\circ} 19.857$ de 2003. En relación con ella son relevantes, por ejemplo, la Circular SII. $n^{\circ} 27$, de 14 de mayo de 2003, que trata de su tributación, pero que, en parte, fue derogada por la Circular SII. n 31, de 1 de junio de 2007 (disponible en línea: http://www.sii.cl/documentos/circulares/2007/circu31.htm).

${ }^{13}$ Ley 19.749 de 2001, Diario Oficial de 25 de agosto de 2001. La Historia de la Ley $n^{\circ} 19.749$, disponible en línea: http://www.leychile.cl/Navegar/scripts/obtienearchivo?id=recursoslegales/10221.3/4235/1/ HL19749.pdf

${ }^{14}$ Decreto $\mathrm{n}^{\circ} 102$ de 2002, Diario Oficial 16 de mayo de 2002.

${ }^{15}$ Mediante la modificación del art. 26 y la introducción del art. 26 bis, en el que fue el Decreto Ley $\mathrm{n}^{\circ} 3.063$ de 1979 (Diario Oficial de 29 de diciembre de 1979) y actualmente, se encuentra en su texto refundido aprobado por Decreto Ley n 3.085, de 1996.
} 
La definición de la microempresa escapa de otras formas típicas societarias y requiere un determinado proceso constitutivo ${ }^{16}$ e inscripción.

Destaca la determinación del familiar que será la cabeza y además la solución chilena opta por regular la microempresa familiar por su contexto urbanístico.

Esto se hace de una manera muy peculiar: no se precisa el parentesco por grados, sino que identifica la microempresa familiar indirectamente, es decir, por el hecho de que la actividad económica se esté ejerciendo en la casa habitación familiar. Siendo una empresa personal, esto se logra mediante la inscripción en la municipalidad de la persona física que se declara "legítimo ocupante" de la casa habitación familiar, aspecto sobre el cual volveré. Asimismo, esta definición abre la posibilidad de incluir a cualquier otro pariente, independiente de su grado y de la necesidad de cohabitación con el legítimo ocupante.

La reglamentación de la microempresa familiar nos ofrece poco más, no preocupándose de enmarcar y definir las principales problemáticas de naturaleza civil y laboral pertenecientes a esta estructura y sus soluciones prácticas. Se instituye así esta microempresa para lograr determinados beneficios fiscales y tributarios, permitiendo su constitución mediante una patente provisoria. A continuación, se revisarán con detalle algunos de estos aspectos.

\section{Algunos problemas relacionados con la microempresa familiar}

La actual normativa no sólo es insuficiente para regular la institución, sino que además adolece de una peculiar técnica legislativa por la cual se incorporó.

En efecto, la técnica utilizada no es de la mejores. La Ley No 19.749/2001, que define la microempresa familiar, introduce los arts. 26 y 26 bis en la Ley

Se permite realizar determinados trabajos por encargo a terceros, como las maquilas, exentas de IVA, de acuerdo con el art. 26 bis. En relación con esta disposición, el Departamento Jurídico de la Dirección del Trabajo, por medio del Dictamen n. 174/02 de 14 de enero de 2005, ha aclarado que la expresión utilizada en el artículo "para todos los efectos legales", "no se refiere ni alcanza a los aspectos laborales (...) sino que se proyecta a los efectos tributario y a trámites de constitución de las demás empresa y autorizaciones municipales".

${ }^{16}$ Cfr. art. 26 del Decreto Ley n 3.085 de 1996, y el art. $3^{\circ}$ del Reglamento de la Ley 19.749. Esta inscripción tiene los efectos de lograr beneficios fiscales y sobre rentas municipales. En relación con los beneficios fiscales y tributarios véase, por ejemplo, la Circular SII. n ${ }^{\circ} 60$, de 18 de octubre de 2002, disponible en línea: http://www.sii.cl/documentos/circulares/2002/circu60.htm; y Circular SII. n 30, de 1 de junio de 2007, disponible en línea: http://www.sii.cl/documentos/circulares/2007/circu31.htm. 
de Rentas Municipales (DL 3063/1979) aunque debiera entenderse que la modificación opera más bien respecto al Decreto 2385/1996 que fija el texto refundido y sistematiza el instrumento de 1979.

Este descuido legislativo tampoco se rectificó en 2005, con la Ley $\mathrm{N}^{\circ}$ 20.031 que -con el propósito de facilitar el funcionamiento de microempresas familiares- "interpreta el art. 26 del DL 3.063/1979", en circunstancias de que, más bien, debería haberse aludido al Decreto 2385.

Por su parte, la reforma posterior operada por el artículo duodécimo de la Ley 20.416 de 2010 -que fija normas especiales para las empresas de menor tamaño- literalmente reclama la modificación del art. 26 del DL 3.063 y no de su texto refundido.

Finalmente, el correcto procedimiento se da por la última reforma del art. 26. La Ley $N^{\circ} 20.494$ de 19 de enero de 2011, que agiliza los trámites para el inicio de actividades de nueva empresa, modifica el Decreto n. $2.385 \mathrm{sin}$ referirse al DL 3.603.

Además, debe destacarse que la reglamentación inicial ha necesitado no sólo de una reforma (por la Ley $\mathrm{N}^{\circ} 20.494$ ) y de una interpretación auténtica del legislador (por la Ley $\left.\mathrm{N}^{\circ} 20.031\right),{ }^{17}$ sino que también se han preocupado de elaborar dictámenes o circulares interpretativas tanto el Minvu, como la DT, el Gobierno de Chile o el SII (vid. infra), aclarando algunas inquietudes o resolviendo problemas prácticos.

Evidenciados estos problemas de técnicas legislativas debe remarcarse que existen otros aspectos que la ley no ha sabido resolver y que necesariamente han debido solucionarse por la jurisprudencia u órganos administrativos, sobre todo frente a la revocación o a la no concesión de patentes, como se verá en los siguientes epígrafes.

\section{i.) La casa habitación familiar.}

A la hora de delimitar el control operacional, no sólo hay que aclarar cuál es el marco interpretativo de la llamada "casa habitación familiar", sino también el de su "legítimo ocupante", ya que la inscripción de la microempresa en la municipalidad se realiza como tal por la persona física del empresario,

\footnotetext{
${ }^{17}$ En relación con la microempresa familiar, la ley indica que "para los efectos de obtener una patente municipal, no se incluye ni se ha debido incluir previamente el permiso de construcción ni la recepción definitiva de las obras constitutivas de la casa habitación familiar en la cual se ejerce la actividad económica que constituye su giro". Sobre su historia legislativa: Congreso NAcional de Chile (editor), Historia de la Ley $n^{\circ}$ 20.031, Biblioteca del Congreso Nacional, Santiago, 2015, documento en .pdf disponible en línea: https://www.leychile.cl/Navegar/scripts/obtienearchivo?id=recursoslegales/10221.3/37606/1/ HL20031.pdf.
} 
separándolo de la forma societaria.

De modo que, por un lado, por casa habitación familiar deberá entenderse la residencia del empresario, ${ }^{18}$ mientras que el legítimo ocupante será "el propietario, poseedor o mero tenedor que tenga derecho a ocupar la casa habitación familiar en que se ejerza la actividad económica" ${ }^{19}$

Por ello, declarar ser legítimo ocupante no necesariamente comporta que el empresario sea el propietario del bien, sino que simplemente puede residir o habitar donde se desarrolla la actividad. ${ }^{20}$

En este sentido, debe también examinarse la relación que puede existir entre el "domicilio comercial" y la residencia del empresario, ya que el sujeto podría o no vivir la mayor parte del tiempo en el lugar donde trabaja. Esto se debe a que el legítimo ocupante puede ser también el mero tenedor, que ha logrado la autorización para ocupar el inmueble por parte del propietario mediante un mandato general. Así, se ha establecido que "dicho documento por sí solo no faculta al legitimario a usar algún inmueble del mandante como casa habitación en su propio beneficio, pues para ello debería mediar algún contrato, como ser de arriendo, usufructo, comodato u otro". ${ }^{21}$

En este caso, un propietario, que vivía la mitad del año en Nueva York, había autorizado a otra persona para usar su inmueble como domicilio comercial, discutiéndose si cuando vivía en Chile lo hacía efectivamente en el inmueble en que se realizaba la actividad de peluquería.

Queda así demostrado que, para que haya microempresa familiar, se exige que la actividad económica se ejerza en la casa habitación familiar. Pero como para constituirla hace falta también la declaración de "legítimo ocupante", se pueden crear estos desajustes.

Cabe también destacar que la declaración de "legítimo ocupante" mediante formulario, ${ }^{22}$ se realiza sin que la municipalidad realice un control inicial de fondo, lo que puede generar problemas prácticos o actividades fraudulentas de personas que, residiendo en otra ciudad, se declaran formalmente como

\footnotetext{
${ }^{18}$ Ahora bien, el art. 5 del Reglamento de la Ley n ${ }^{\circ} 19.749$ se refiere a la "residencia del o de los empresarios". Se produce aquí un tecnicismo, ya que la microempresa es de estructura unipersonal, toda vez que se constituye mediante la declaración del microempresario como legítimo ocupante. La presencia de más de un microempresario denotaría una estructura societaria más compleja.

${ }^{19}$ Art. 5, Reglamento de la Ley ${ }^{\circ} 19.749$.

${ }^{20}$ Circular Minvu n ${ }^{\circ} 118$ (DDU 126), interpretativa de la Ley $n^{\circ} 19.749$.

${ }^{21}$ Corte de Apelaciones de Valparaíso, 11 de octubre de 2012, Rol n ${ }^{\circ}$ 671-2012.

${ }^{22}$ Art. 3 b, Reglamento de la Ley n ${ }^{\circ} 19.749$.
} 
microempresarios y ocupantes de un inmueble que ya no habitan. ${ }^{23}$ Esto se observa con ocasión de una no renovación de patente de alcoholes de una hostería en la Araucanía cuyo microempresario trabajaba, al mismo tiempo, en un hospital en Santiago. Aunque exista la presunción de domicilio del art. $64 \mathrm{CC}$, esta fue derrotada dado que el microempresario no fue habido personalmente en el inmueble en reiteradas fiscalizaciones.

En lo que respecta a la manera en que se delimita la "casa habitación familiar", la circular MINVU n. 118 (DDU 126), interpretativa de la Ley 19.749 , en parte la amplía, cuando afirma que, en viviendas con terreno propio, la actividad empresarial podrá desarrollarse dentro de los límites del terreno y no obligatoriamente en el área construida.

Con todo, no puede apoyarse un concepto excesivamente amplio, ya que, por ejemplo, no se permitiría una actividad de restaurante en un inmueble en que se ubica, además, otro local comercial de un tercero, compartiendo ambos un patio común. En el mismo inmueble, el recurrente tiene construidas unas cabañas para un eventual giro comercial. Se considera que "el inmueble en cuestión, al ser compartido comercialmente con el aludido tercero y en que el propio recurrente ejercerá otra actividad comercial, no puede quedar comprendido dentro del concepto de casa habitación familiar que prevé la normativa en comento". ${ }^{24}$

Corresponde preguntarse también si parte de la actividad empresarial puede realizarse en la casa y otra parte en la vía pública. Frente al silencio legislativo, los tribunales incluyen también la que se desarrolle en la vía pública, sin que ello obste a que la microempresa sea familiar y que su actividad se entienda preeminente realizada en la casa habitación. Se trataba de un "taller de estructuras metálicas" que después de algunos años -y siempre habiendo obtenido los permisos correspondientes- pasó a ser una "mecánica automotriz y venta de repuestos de automóviles", dedicándose a la reparación de vehículos. ${ }^{25}$

Finalmente, ha de destacarse que, aunque el trabajo se ejecute en una casa,

\footnotetext{
${ }^{23}$ Esto se observa con ocasión de una no renovación de patente de alcoholes de una hostería en la Araucanía cuyo microempresario trabajaba, al mismo tiempo, en un hospital en Santiago. Aunque exista la presunción de domicilio ex art. $64 \mathrm{CC}$, esta fue derrotada dado que el microempresario no fue habido personalmente en el inmueble en reiteradas fiscalizaciones. Corte de Apelaciones de Temuco, 21 de octubre de 2016, Rol $\mathrm{n}^{\circ}$ 5.440-2016.

${ }^{24}$ Corte de Apelaciones de Temuco, 26 de junio de 2007, Rol n ${ }^{\circ} 419-2007$.

${ }^{25}$ Infructuoso resultó el recurso del vecino para cerrar la empresa: Corte de Apelaciones de San Miguel, 22 de abril de 2013, Rol n 56-2013, Id. VLex: VLEX-586506374.
} 
no debiera restringirse el libre desarrollo empresarial. Así, sería sancionable la prohibición municipal de instalación de publicidad que sirva para promocionar el negocio correspondiente, por vulnerar el art. 21 n. 19 de la Constitución. ${ }^{26}$

ii.) Su constitución y sus trámites.

La constitución de la microempresa familiar recibe un trato favorable, ya que no se le aplican las reglas generales dictadas en materias de urbanismo, que exigen la recepción definitiva de las obras para otorgar una patente, a tenor del art. 145 de la Ley General de Urbanismo y Construcciones.

Efectivamente, después de la Ley $\mathrm{N}^{\circ} 20.031 / 2005$, no queda duda de que la autorización para conseguir una patente municipal no necesita la obtención previa del permiso de construcción ni de la recepción definitiva de las obras constitutivas de la casa habitación familiar. Las dudas fueron provocadas por algunos Dictámenes de la Contraloría General de la República, ${ }^{27}$ en que se sostuvo lo contrario. Pero los tribunales ${ }^{28}$ y el legislador, confirmando el trato favorable que debe concederse a esta tipología empresarial, dejan claro que no es así. De modo que una vez reunidos los requisitos constitutivos de la microempresa ésta podrá empezar su actividad de inmediato, especialmente gracias a la posibilidad de pedir una patente provisional, de duración no superior a un año. La Corte Suprema deja claro que las municipalidades sólo pueden otorgar patentes provisorias por este plazo, por estimarlo suficiente para que el contribuyente cumpla con las disposiciones legales en relación con su patente. De lo contrario, podría ponerse fin a la actividad empresarial. ${ }^{29} \mathrm{En}$ consecuencia, las municipalidades necesariamente deberán aceptar el inicio de las actividades en presencia de los requisitos formales de constitución, aunque deberán informar acerca el resultado de eventuales investigaciones sumarias

\footnotetext{
${ }^{26}$ Dictamen CGR n ${ }^{\circ}$ 41.523, 11 julio de 2012, Id. vLex: VLEX-406752430.

${ }^{27}$ Dictamen CGR n ${ }^{\circ} 51.504,14$ de noviembre de 2003, documento disponible en línea: http://www. contraloria.cl/appinf/LegisJuri/jurisprudencia.nsf/2c14219fb5bc2941042570990075ce9f/d953364e9683e a41842571bd00520bc3?OpenDocument. Este dictamen, antes de la promulgación de la Ley $\mathrm{n}^{\circ} 20.031$ se aclaró y rectificó por el Dictamen CGR n 8.297, de 19 de febrero de 2004 (documento disponible en línea: http://www.contraloria.cl/appinf/LegisJuri/jurisprudencia.nsf/2c14219fb5bc2941042570990 075ce9f/a0fe2eecc347e2e9842571bd004aa87a?OpenDocument). El primero se había confirmado por otro posterior, pero anterior a la nueva ley: Dictamen CGR n ${ }^{\circ} 24.012$, de 19 de mayo de 2005, Id. vLex: VLEX-238908346.

${ }^{28}$ También por los tribunales: v.gr. Corte de Apelaciones de Santiago, 31 de diciembre de 2010, Rol $\mathrm{n}^{\circ}$ 6.591-2010.

${ }^{29}$ Corte Suprema, 3 de noviembre de 2016, $3^{\text {a }}$ Sala (constitucional), Rol n ${ }^{\circ} 41.069-2016$.
} 
que realice posteriormente. ${ }^{30}$

Ahora bien, la posibilidad de utilizar la patente comercial provisional es meramente una facultad, pudiéndose pedir directamente la definitiva. Esta disposición impide reclamar una indemnización a la municipalidad por la eventual falta de servicio que comportaría un retraso en apertura de la actividad. Así, se ha denegado la demanda de daños por falta de servicio (art. 142 Ley 18.695), por la tardanza en la concesión de la patente a aquel empresario que solicitó inicialmente la definitiva y que pudo iniciar la actividad sólo 21 días hábiles después. El empresario, al abrir un circuito de Paint Ball y cancha de minigolf en una localidad de veraneo y al haber solicitado el inicio de la actividad en plena época estival - el 25 de enero- reclamaba no solamente un daño emergente y lucro cesante, sino también daño moral. La petición se desestimó porque se consideró aquel un plazo razonable para valorar la concesión de una patente definitiva, además de otros aspectos probatorios. ${ }^{31}$

En este punto es conveniente evidenciar situaciones peculiares, como las que se provocan en zonas residenciales. Efectivamente, el hecho de que la actividad empresarial no esté prevista en el plan regulador de un barrio residencial no es razón suficiente para excluir la normativa especial sobre microempresa familiar, que permite instalar el local comercial, incluso, con la oposición de vecinos. ${ }^{32}$ Una vez cumplidos los requisitos predispuestos por la ley, estos reclamos no deberían tener acogida. ${ }^{33}$

Por otro lado, si constituir una microempresa familiar importa la ausencia de determinadas exigencias para obtener la patente municipal, posee otras, como aquellas de carácter sanitario (vid. art. 4 del Reglamento sobre la microempresa familiar $)^{34}$ y las que se relacionan intrínsecamente con la casa donde se desarrolla la actividad. Así, la microempresa requiere la calificación

\footnotetext{
${ }^{30}$ Dictamen CGR n ${ }^{\circ} 11.725$, de 17 de febrero de 2014.

${ }^{31}$ Juzgado de Letras de Casablanca, 13 de diciembre de 2011, Rol n ${ }^{\circ}$ 12.657-2010.

${ }^{32}$ Concretamente, una boutique: Corte de Apelaciones de Antofagasta, 15 de mayo de 2012, Rol n ${ }^{\circ} 200$ 2012, Id. VLex: VLEX-380192510.

${ }^{33}$ Como el reclamo de un vecino por los ruidos molestos de un taller de reparación de vehículos: Corte de Apelaciones de San Miguel, 22 abril de 2013, Rol n 56-2013, Id. VLex: VLEX-586506374.

${ }^{34}$ Por el art. 4 del Reglamento sobre la Microempresa Familiar: "para otorgar la patente, así como la autorización para funcionar en la casa habitación familiar, la municipalidad no considerará las limitaciones relativas a la zonificación comercial o industrial que contemplen las respectivas ordenanzas municipales ni las autorizaciones que previamente deben otorgar las autoridades sanitarias $\mathrm{u}$ otras que contemplen las leyes y que afecten a dicho inmueble, excepto las limitaciones o autorizaciones dispuestas en el Decreto Supremo № 977, de 1997, del Ministerio de Salud, que aprobó el Reglamento Sanitario de los Alimentos". En relación con el art. 145 de la Ley de Urbanismo, v. Corte de Apelaciones de Santiago, 9 de diciembre de 2015, Rol n ${ }^{\circ} 1.552-2015$.
} 
de actividad inofensiva por la autoridad sanitaria y en caso que trabaje con alimentos, debe poseer una ulterior y segunda autorización de la SEREMI de Salud respectiva. Efectivamente los estándares de habitabilidad, como los del Programa de Fondo Solidario de Vivienda y Protección del Patrimonio Familiar del Instituto de la Vivienda (INVI) ${ }^{35}$ o por el Fondo de Solidaridad e Inversión Social (Fosis), ${ }^{36}$ podrían limitar el desarrollo de la actividad, aunque se consiguiera la patente provisional inicial.

En relación con la actividad inofensiva pueden aportarse dos referencias, una estrictamente interpretativa de la microempresa familiar y otra relativa al concepto de microempresa no solamente familiar.

Bajo el primer punto de vista se consideran inofensivas "todas aquellas que no producen: ruidos $\mathrm{u}$ olores molestos, vibraciones o trepidaciones, emisiones de material particularmente nocivo y gases peligrosos o que facilitan la proliferación de vectores tales como roedores, moscas y otros insectos, inseguridad por incendio y otros siniestros de similar naturaleza, etc..". ${ }^{37}$

Bajo el segundo punto, por el art. 4.2 Ley $\mathrm{N}^{\circ} 20.563$ que regulariza construcción de bienes raíces destinados a microempresas y equipamiento social, considera como inofensiva aquella "microempresa que no produce daños ni molestias a las personas, comunidad o entorno, controlando y neutralizando los efectos del proceso productivo o de acopio, siempre dentro del propio predio e instalaciones, resultando su funcionamiento inocuo, lo que será certificado por la autoridad sanitaria correspondiente o quien ella designe". Para efectos de esta ley, es importante destacar que la microempresa familiar puede regularizarse. ${ }^{38}$

El legislador chileno también legitima realizar la actividad en un condominio, previa autorización del comité de administración respectivo. No queda duda tampoco sobre la aprobación de ejercitarla en porciones de terreno

\footnotetext{
${ }^{35}$ INVI - FAU, Bienestar Habitacional: Guía de Diseño para un Hábitat Residencial Sustentable. INVI-FAU Universidad de Chile, Santiago, 2004 (Jirón, Toro, Caquimbo, Goldsack, Martínez coords.), documento disponible en línea: $\mathrm{http}: /$ www.arqenergia.cl/images/pdf/Bienestar\%20Habitacional.pdf, 19 de abril de 2018.

${ }^{36}$ SGP-Fosis (editores), Definición de estándares técnico-constructivos para dar solución a las condiciones minimas del programa habitabilidad Chile Solidario, MIDEPLAN, Santiago, 2011, documento en archivo .pdf, disponible en línea: http://sigec.mideplan.cl/sigec/docs/2620/est_ndares\%20tecnicos.pdf, 19 de abril de 2018

${ }^{37}$ Circular MINVU n 118 (DDU 126), interpretativa de la Ley 19.749.

${ }^{38}$ Circular MINVU n ${ }^{\circ} 302$, de 31 de julio de 2012, complementada por Circular $n^{\circ} 469,4.22016$, DDU 321 , que trata el concepto de microempresa inofensiva en su párrafo ${ }^{\circ} 4$, p. 6 .
} 
común entregadas en usufructo al microempresario. ${ }^{39}$ Sin embargo, queda por ver si es necesaria una autorización expresa o no. Este requisito puede interpretarse de manera flexible, pues debe constatarse que la venia puede deducirse por un comportamiento concluyente, como cuando, habiéndose otorgado una patente municipal por más de veinte años, ningún miembro del condominio se opuso a que la actividad se realizara en el antejardín común. En este sentido, debería acogerse el recurso del microempresario frente a la petición de la municipalidad de autorización de los comuneros; de lo contrario, se atentaría al principio de libertad empresaria radicado en el art. $21 \mathrm{n}^{\circ} 21 \mathrm{de}$ la Constitución. ${ }^{40}$

iii.) Las actividades desarrollables en el marco de las limitaciones urbanísticas y administrativas.

La normativa exige expresamente que la microempresa familiar desarrolle una actividad lícita, excluyendo actividades peligrosas, contaminantes o molestas. ${ }^{41}$ Pero, aunque el listado no sea exhaustivo sino orientativo, ${ }^{42}$ podrá valorarse en cada caso particular si la actividad llega a provocar molestia o contaminación, ${ }^{43}$ aunque, en abstracto, no sea parte de la enumeración. En este sentido, puede integrarse una actividad no incluida o denegarla, como en caso de infracción a las autorizaciones sanitarias de un apart hotel. ${ }^{44}$

En relación con el hecho de que la actividad no deba ser molesta, debe tenerse en cuenta que, al enmarcar la microempresa en el hogar familiar, indirectamente se le somete a la legislación sobre contaminación acústica. Lo anterior, limita en forma implícita su creación o su prosecución dentro de un condominio.

Efectivamente, además de la autorización de los demás copropietarios, será importante que la actividad se someta a restricciones sonoras. Efectivamente el Decreto 38 de 2001, sobre emisión de ruidos molestos generados por fuentes fijas, elimina el concepto de "molestia". El considerando de texto legislativo

\footnotetext{
${ }^{39}$ Circular MINVU n ${ }^{\circ} 118$, cit. (n. 37).

${ }^{40}$ Concretamente era una actividad de joyería que se desarrollaba en el antejardín y en la casa familiar situada en la primera planta: Corte de Apelaciones de Santiago, 31 diciembre de 2010, Rol n 6.591-2010.

${ }^{41}$ Interpretación conjunta de los arts. 26 del Decreto 2.085 y arts. 2 y 3 letra c) del Reglamento sobre microempresa familiar.

${ }^{42}$ V. anexo I de la Circular MINVU n. 118, cit. (n. 37).

${ }^{43}$ Este principio puede encontrarse en Corte de Apelaciones de San Miguel, 22 de abril de 2013, Rol. $\mathrm{n}^{\circ}$ 56-2013, Id. VLex: VLEX-586506374.

${ }^{44}$ Corte de Apelaciones de Santiago, de 10 de abril de 2015, Rol n 7.892-2014.
} 
advierte que "el concepto de molestia fue eliminado de la norma de emisión dado los problemas de interpretación a que daba lugar, y porque el concepto de molestia no está directamente relacionado con un nivel de ruido determinado".

Así, por ejemplo, en el radio urbano, dicha contaminación no puede ser superior a 55 decibeles en horario de 7 a 21 horas o a 45 en las horas nocturnas (21-7 horas del día siguiente). Dado que los valores de la contaminación acústica (art. 7) varían dependiendo de la zona endémica de referencia (zona I, II, II, IV o rural), se limitan de facto muchas actividades empresariales, sobre todo de industria o artesanía. Además, es oportuno recordar que por el art. 32 de la Ley $\mathrm{N}^{\circ} 19.537$ de 1997 sobre copropiedad inmobiliaria "tampoco se podrá ejecutar acto alguno que perturbe la tranquilidad de los copropietarios o comprometa la seguridad, salubridad y habitabilidad del condominio o de sus unidades, ni provocar ruidos en las horas que ordinariamente se destinan al descanso, ni almacenar en las unidades materias que puedan dañar las otras unidades del condominio o los bienes comunes".

En lo referido al concepto de licitud, deben prohibirse aquellas actividades que impliquen juegos de azar. Así, la municipalidad no está obligada a atenerse al resultado del peritaje que acredite que se trata de un juego de destreza y no de azar. No sólo se deberá tener en consideración el catálogo que identifica los juegos de azar, sino que podrá denegarse mediante cualquier medio probatorio pertinente. Las municipalidades pueden autorizar patentes de videojuegos y play station que no den premios en dinero y podría solamente autorizar juegos de destreza y no de azar. No obstante, se prohíbe la implantación de unas máquinas "frutilla, mañanita, fruit, cocktail". ${ }^{45}$

Ahora bien, una de las problemáticas más relevantes se refiere a la posibilidad de expedir bebidas alcohólicas en la microempresa familiar. Aunque la Ley sobre Expendio y Consumo de Bebidas Alcohólicas (Ley 19.925) exige en su artículo 14 la independencia absoluta del local de expendio con toda casa habitación, esto no es razón suficiente para denegar la patente, como se da en caso de un restaurant de turismo. ${ }^{46}$ Por ello, la revocación de una patente fundada en que en un local se consume alcohol, solo por haber

${ }^{45}$ Corte de Apelaciones de Valdivia, 3 de diciembre de 2014, Rol n ${ }^{\circ} 318-2014$. A estos efectos, cfr. art. 2259 CC y Ley 19.995 que establece las bases generales para la autorización, funcionamiento y fiscalización de casinos. En este sentido son importantes las Circulares de la Superintendencia de Casinos que establece cuáles juegos son de azar (v.gr. Resolución $\mathrm{n}^{\circ} 157$ de 2006, Circular $\mathrm{n}^{\circ}$ 966, de 28 de agosto de 2012, y sobre el concepto de máquina de azar: Resolución exenta $n^{\circ}$ 284, de 18 de junio de 2013).

${ }^{46}$ Corte de Apelaciones de Valparaíso, 7 de abril de 2006, Rol n 881-2016. Véase también: Corte de Apelaciones de Temuco, 26 de julio de 2007, Rol n 419-2007. 
encontrado cerveza en el refrigerador sin constatar si estaba destinada a consumo particular o al expendio al público, podría ser contraria al art. $19 \mathrm{n}$. 21 y 24 de la Constitución.

Ciertamente, la microempresa no se encuentra excluida a priori del cumplimiento de la normativa propia de la Ley sobre Expendio y Consumo de Bebidas Alcohólicas. ${ }^{47}$ Gracias a ello, podría incluso autorizarse elaboración de cerveza o licores artesanales bajo la modalidad de empresa familiar. ${ }^{48}$ En esto también ayuda el hecho de que el concepto de casa habitación puede ampliarse al terreno de la casa y no obligatoriamente al área construida.

\section{La foto panorámica actual}

Analizando el panorama jurídico actual hay que constatar que el legislador chileno propone una definición de microempresa familiar sin otorgar la regulación de su figura complementaria, es decir aquella de una empresa familiar que no sea micro. Esta última, por lo tanto, en ausencia de expresa reglamentación, puede asumir cualquier tipología societaria y de facto pierde su peculiaridad principal, el de ser nicho de una actividad estrictamente familiar.

La inexistencia en Chile de una regulación ad hoc de la empresa familiar (que no sea microempresa), comporta que, a lo que debería ser un instituto jurídico independiente, se les aplique cualquier forma societaria típica, personalista y/o capitalista. Se aleja así de su característica intrínseca: el estar formada por un grupo humano unido por lazos afectivos y de sangre. Se abandona su origen natural y se le da una visión impersonal y abstracta, pues poco importa que los órganos de estas sociedades capitalistas estén formados,

\footnotetext{
${ }^{47}$ Dictamen CGR n ${ }^{\circ} 33.433$, de 30 mayo de 2013: Gianfranco Bongiovanni García (elaboración de pizzas y expendio de bebidas envasadas de fábricas autorizadas), reclamando en contra de la Municipalidad de Las Condes, disponible en Vlex, en línea: http://app.vlex.com/\#vid/439303998; Dictamen CGR n 9.967, de 6 de abril de 2005, Daniel Rojas Herrera reclamando en contra de la Municipalidad de Buin; disponible en línea: http://www.contraloria.cl/LegisJuri/DictamenesGeneralesMunicipales.nsf/FormImpresionDicta men?OpenForm\&UNID=642CF1C0A733350B03257E21004B8963, Dictamen CG de Municipalidad de Pucón, ${ }^{\circ} 44.440$, de 29 de septiembre de 2008, documento disponible en línea: http://www.contraloria.cl/ appinf/LegisJuri/jurisprudencia.nsf/2c14219fb5bc2941042570990075ce9f/68cb9c86db6d7220842574d00 05b23b0?OpenDocument; Dictamen CGR n ${ }^{\circ}$ 12.985, de 2 de marzo de 2011 (Mini mercado con expendio bebidas alcohólicas, Rubén Zanberk Davis, reclamando en contra de la Municipalidad de Talagante), documento disponible en línea: http://www.contraloria.cl/appinf/LegisJuri/jurisprudencia.nsf/2c14219fb5 bc2941042570990075ce9f/4ca723f80298f4498425784e0061f5aa?OpenDocument.

${ }^{48}$ Dictamen CG de la Municipalidad de Cerro Navia, ${ }^{\circ} 72.208$, de 4 de octubre de 2016, en http://www. contraloria.cl/LegisJuri/DictamenesGeneralesMunicipales.nsf/FormImpresionCompleto?OpenForm\&U $\mathrm{NID}=9 \mathrm{~B} 67277 \mathrm{~B} 2 \mathrm{~F} 52883103258044005 \mathrm{C} 3 \mathrm{~F} 58$.
} 
en todo o parte, por miembros de la misma familia.

Amoldar la empresa familiar a una estructura societaria tipificada implicaría considerarla más empresa que familia. Por ello, ésta debiera corresponder a un modelo definido por un empresario individual, pero con una estructura plurisubjetiva interna. Debería conformarse como un núcleo de miembros caracterizado por una solidaridad familiar; una solidaridad que, en parte, se funda en el antiguo concepto de hacienda radicada en la casa patronal y que también asume que el criterio jerárquico del antiguo pater familias ${ }^{49}$ ha evolucionado, permitiendo que cada familiar tome el papel de empresario. En definitiva, desde esta perspectiva, la empresa familiar es un entorno humano que se protege y que contribuye con el desarrollo de la economía y de la sociedad. Efectivamente, algunos modelos que luego no se implantaron tenían conciencia de regular de algún modo nuevos fenómenos de explotación. Por ejemplo, lo que se preveía con la reforma agraria de 1965 era dar la posibilidad a los campesinos de valorar el trabajo en una propiedad familiar o en comunidad.

Según el prototipo de empresa familiar stricto sensu, el estatus de familiar, la gestión empresarial y el patrimonio son tres elementos que se entremezclan y forman un conjunto armónico y único. En cambio, en un modelo que puede asumir cualquier estructura societaria, estos tres elementos corren el riesgo de considerarse independientes $\mathrm{y}$, en determinadas condiciones, prescindir el uno del otro.

La ausencia de una reglamentación expresa de la empresa familiar en Chile permite, por lo tanto, que ésta pueda asumir tanto la forma de una PyME, como de una sociedad de dimensiones más amplias. Esta manera de entenderla, conduce a subordinarla a una heterogénea normativa, tal vez incluso antitética. De hecho, al estado actual, una empresa familiar puede considerarse como un consumidor y someterse a esta regulación si asume la fisionomía de micro o pequeña empresa (cfr. art. 9.2 Ley $\mathrm{N}^{\circ} 20.416$ ).

Frente a este escenario se perfila otro, en el cual los miembros de una

\footnotetext{
${ }^{49}$ Efectivamente, algunos modelos que luego no se implantaron tenían conciencia de regular de algún modo nuevos fenómenos de explotación. Por ejemplo, lo que se preveía con la reforma agraria de 1965 era dar la posibilidad a los campesinos de valorar el trabajo en una propiedad familiar o en comunidad. A tal fin el art. 67 de dicho texto decía que: "el asentamiento campesino es la etapa inicial en la organización social y económica de los campesinos, en la cual la explotación de las tierras expropiadas se realiza bajo forma jurídica de una sociedad civil -Sociedad Agrícola de Reforma Agraria- entre la Corporación de Reforma Agraria -CORA- y los campesinos, futuros beneficiarios de la tierra. El período que media entre la toma de posesión material del predio expropiado y la asignación de la tierra es de tres años...". En definitiva, al modelo de comunidad se aparejaba la gestión familiar, basado sobre normas más bien internas, según la estructura del pater familias.
} 
familia posean -en calidad de socios- la mayoría de participación en una sociedad, y en este sentido, se considere familiar, porque es controlada por un único núcleo.

Esta situación tiene las dos caras de la medalla. De acuerdo con la primera, efectivamente el paso al modelo societario puede ser necesario en la realidad chilena, cada vez que la microempresa familiar desborde su estructura legal debido, por ejemplo, a su crecimiento económico (más de 1.000 unidades de fomento o más de 5 trabajadores externos). En estos casos, la actividad empresarial necesitará cambiar su estructura y amoldarse a una con forma societaria. Dejaría de aplicársele su estatuto ad hoc, perdiendo en parte su naturaleza estrictamente familiar. El familiar pasaría a ser socio de una agrupación más organizada, transformando una unidad económica fundada en la solidaridad familiar, en la profesionalización de la misma.

La otra cara de la medalla es que la acotada y peculiar definición de esta microempresa conduce a que múltiples negocios no puedan beneficiarse de ventajas fiscales y tributarias, debido al restringido ámbito de aplicación de la normativa nacional, sobre todo el hecho de que la actividad deba realizarse en la casa familiar, es decir en un preciso y limitado contexto urbanistico. Todo esto va en contra, no sólo de una política más perfeccionada de desarrollo empresarial, sino que del art. $19 \mathrm{n}^{\circ} \mathrm{s} .21$ a 24 de la Constitución.

\section{LA RATIO DE LA REGULACIÓN DE LA EMPRESA FAMILIAR}

Si se analiza la ratio que ha conducido a la regulación de la microempresa familiar en Chile, es patente que la función principal y, quizás, exclusiva, es proporcionar beneficios fiscales y tributarios ${ }^{50}$ o conceder patentes provisorias que eviten las dilaciones de las situaciones generales. Otros aspectos, como los endofamiliares o laborales, quedan al margen o se encuentran tratados embrionariamente (vid. art. 26 bis).

La empresa familiar, sin embargo, necesita una visión de contexto más amplio, que no pierda de vista la imprescindible preponderancia de su elemento característico. Efectivamente, la connotación familiar impone que la actividad económica se mida en relación con las efectivas relaciones patrimoniales que se generan tanto dentro como fuera de este contexto. Por ello, no sólo es

\footnotetext{
${ }^{50}$ Relacionada con ello es relevante, por ejemplo, la Circular SII. $n^{\circ}$ 60, de 18 de octubre de 2002, documento disponible en línea: http://www.sii.cl/documentos/circulares/2002/circu60.htm, que trata su tributación, en parte derogada por la Circular SII. $n^{\circ} 30$, de 1 de junio de 2007, documento disponible en línea: http://www.sii.cl/documentos/circulares/2007/circu31.htm.
} 
oportuno valorar la forma en que debe gestionarse y repartirse el patrimonio, sino cómo y en qué medida deba proyectarse hacia el exterior. Entra en juego entonces un tercer factor, el de la regulación del patrimonio, aspecto que no es baladí y que debe moverse armoniosamente entre los elementos de la empresa y la familia. Dependiendo del punto de vista analizado, los tres estatus de miembro, familiar y socio asumirán connotaciones diferentes.

La necesidad de crear un instituto jurídico per se nace de varias exigencias, como la tutela del trabajo familiar o la protección individual de cada miembro. ${ }^{51}$

Esta empresa nace históricamente en un contexto agrario, en que se manifestaba la originaria comunidad tácita $\operatorname{familiar}^{52}$ y se justifica por el progresivo abandono de la familia patriarcal, para dar paso a una mayor atribución de derechos a sus miembros. Y aunque es innegable que muchas prestaciones se realizan a título gratuito, inspiradas por el principio affectionis vel benevolentiae causa, múltiples e interesantes interrogantes se presentan en un contexto moderno; tales como si, efectivamente, la presunción de gratuidad de la actividad de un familiar puede ser vencida, o en qué medida pueden tutelarse los aspectos patrimoniales y no patrimoniales del miembro que coopera en este contexto laboral. Ejemplo de ello se presenta en el ordenamiento español que regula la presunción de no laboralidad del familiar en el Real Decreto Legislativo 2/2015, de 23 octubre, por el que se aprueba el texto refundido de la Ley del Estatuto de los Trabajadores (vid. art. $1.3 \mathrm{e}$ ): "Se excluyen del ámbito regulado por esta ley (...) los trabajos familiares, salvo que se demuestre la condición de asalariados de quienes los llevan a cabo. Se considerarán familiares, a estos efectos, siempre que convivan con el empresario, el cónyuge, los descendientes, ascendientes y demás parientes por consanguinidad o afinidad, hasta el segundo grado inclusive y, en su

\footnotetext{
${ }^{51}$ En este sentido es útil aportar de un ordenamiento, el italiano, que ha decidido regularla expresamente, véase: BusNELli, Francesco D, "Impresa familiare e aziende gestite da entrambi i coniugi", Rivista trimestrale di diritto e procedura civile., 1977, p. 1492; ANDRINI, Maria Claudia; VITTORIA, Daniela, Azienda coniugale e impresa familiare en Trattato di Diritto commerciale e di diritto pubblico dell'economia, dirigido por Francesco Galgano, Cedam, Padova, 1989, Vol. XI; Ghidin, M., L'impresa familiare, Cedam, Padova, 1977; Pannuccio. Vicenzo, Enciclopedia del diritto, Giuffre, Milano, 2000, ad vocem "impresa familiare"; Prosperi, Francesco, "L'impresa Familiare", en Busnelli, F. (director), Comentario al codice civile (fondato da Piero Schlesinger), Giuffrè, Milano, 2006; PAladin, Mauro, "L'impresa familiare", en Bonilini, G. (director), Trattato di diritto di famiglia, II: Il regime patrimoniale della famiglia, UTET, Torino, 2016, pp. 1737-1782.

${ }^{52}$ Para el concepto de Comunidad tácita familiar, véase VIGNOLI, G., "Comunione tacita familiare", Enciclopedia Giuridica (Treccani, Roma), 1988, VII; Franceschelli, V., "Comunione tacita familiare", Digesto Civile, UTET, Torino, 1988, III.
} 
caso, por adopción. ${ }^{53}$

La regulación de este instituto permite evitar las injusticias que un fenómeno piramidal patriarcal podría suscitar, al tener un único sujeto -el microempresario- en el centro de poder, pues, por mucho que imperen cánones de equidad, se pone en riesgo la repartición de derechos a los demás miembros.

Disciplinar la empresa familiar (y no solo la microempresa) permitirá crear un puente entre la total gratuidad y el ámbito estrictamente subordinado, característico de la relación laboral. Por lo tanto, su tipificación predispondría un estatuto jurídico suis generis al cual se puede acudir deliberadamente. En este contexto, la eficacia constitutiva de la empresa dependerá del acuerdo de sus miembros, ya que, en caso contrario, la remisión debería hacerse a la normativa ordinaria (de derecho societario o de derecho laboral).

En definitiva, la ratio de la tipificación de la empresa familiar, más que proporcionar beneficios fiscales y tributarios, implicaría regular todo tipo de situación profesional que, aunque tenga un carácter continuativo, no pueda definirse estrictamente como laboral por su peculiaridad y circunstancias.

Por tanto, aunque el legislador chileno haya optado por normar sólo una especie de empresa familiar, esta reglamentación es insuficiente. Por un lado, porque se omite organizar la categoría más amplia -que es la empresa familiar$\mathrm{y}$, por otro, porque no se regulan los aspectos relativos a la protección laboral y patrimonial de los miembros que desarrollan una actividad dentro del ambiente familiar empresarial.

La ausencia de una adecuada reglamentación obliga a identificar cuáles son los deberes y derechos de los miembros. En la práctica, la preocupación pasa de ser un problema familiar, como conjunto de personas afectivamente vinculadas, a un asunto más bien patrimonial, intentando garantizar la transmisibilidad de las cuotas societarias a los futuros familiares. Por eso la preocupación jurídica más común es la elaboración de un protocolo "familiar", que más bien es "patrimonial", mediante el cual quiere conseguirse que las cuotas sociales o la administración y el control sigan en mano de un determinado grupo. Este último contexto, a mi entender, se pierde de vista la verdadera ratio de la empresa familiar.

\footnotetext{
${ }^{53}$ Sobre el punto, véase FerRante, Alfredo, "El trabajo familiar en el Derecho español: el trabajo ¿autónomo? de sus miembros entre las mallas laborales y civiles", Estudios Financieros. Revista de trabajo y seguridad social, 2007, $\mathrm{n}^{\circ} 292$, pp. 61-112.
} 


\section{A MODO DE EJEMPLO: EL MODELO ITALIANO}

Con la finalidad de ahondar en algunos puntos importantes relacionados con la empresa familiar, considero útil aportar la comparación con el modelo italiano, ya que ella queda regulada, desde la reforma del derecho de familia de 1975, en el art. 230 bis del Código Civil y desde 2016 en el art. 230 ter, relativo a las empresas familiares en las que intervenga un conviviente de hecho. ${ }^{54}$

Así, la empresa familia italiana se ha definido 55 "como un péndulo que se mueve entre la disciplina societaria y la del trabajo subordinado, rozando las dos, pero no siendo ninguna de las dos". Sin efectuar un análisis exhaustivo del modelo italiano, ${ }^{56}$ es oportuno destacar que se prevé una empresa familiar cuya actividad queda desvinculada del hogar, en un concepto totalmente expansivo que permite el libre desarrollo económico. Al tipificarse con una regulación propia, esta institución se hace incompatible con cualquier otra disciplina o forma societaria ${ }^{57}$ relacionada.

Un punto relevante es el abanico de derechos predispuesto por la ley para aquel familiar que proporcione de manera continua su apoyo en la empresa. Para estos efectos se considera cualquier tipo de aportación, incluso la que sea indirectamente relacionada con el desarrollo de la empresa, como puede ser

\footnotetext{
${ }^{54}$ Efectivamente es importante destacar que, debido a la reglamentación de los convivientes de hecho -por la reciente Ley $\mathrm{n}^{\circ} 76-2016$, de 20 de mayo- se introduce paralelamente a la reglamentación de la empresa familiar (regulada por el art. 230 bis del Código Civil italiano), el art. 230 ter que se dedica a desglosar los derechos del conviviente de hecho que preste con regularidad una actividad en la empresa familiar del conviviente. V.gr. véase GHIDONI, Luca, "Unione civile e impresa familiare: la disarmonia di una mera estensione normativa", Famiglia e Diritto, 2017, n 7, pp. 701-705.

Anteriormente el problema era debatido: por todos, véase OBERTO, Giacomo, "Ancora sulla pretesa gratuità delle prestazione lavorative subordinate rese dal convivente more uxorio", Famiglia e Diritto, 2016, $\mathrm{n}^{\circ} 2$, pp. 132-151.

${ }^{55}$ IRTI, Natalino, "L'ambigua logica dell'impresa familiare”, Rivista di diritto agrario, 1980, p. 530.

${ }^{56}$ Sobre el análisis de la empresa familiar en Italia en idioma español, v.: FERRANTE, Alfredo, "Aportaciones comparativas para la definición jurídica de un instituto: la empresa familiar en Italia", Revista de Derecho de Sociedades, 2004, n 23, pp. 465-484.

${ }^{57}$ Cassazione Civile, sec. unite, $\mathrm{n}^{\circ} 23.676$, de 6 de noviembre de 2014. Para un texto y un comentario, v.gr. véase a Scotті, Anna, "Dalla Corte di Cassazione un'occasione er tornare a riflettere sulla compatibilità tra impresa familiare e forme collettive di impresa", Corriere Giuridico, 2015, n 10, pp. 1249- 1261; Bona, Carlo, "L'art. 230 bis c.c. e la partecipazione del familiare ad una società", Foro Italiano, 2015, Vol. 140, $\mathrm{n}^{\circ}$ 1; BARILlÁ, Giovanni Battista, "Impresa familiare e forma societaria: due modelli incompatibili", Nuova giurisprudenza civile e commentata, 2015, $\mathrm{n}^{\circ}$ 4, parte I, p. 355; CorsI, Francesco, "Impresa in familia, impresa familiare e società", Giurisprudenza commerciale, 2015, n 3, II, p. 522. También en Italia se requiere la constitución formal para logar los beneficios fiscales y separar la empresa familiar de otros modelos: Cassazione Civile n. 2472, 10 de febrero de 2017 en base de datos De jure.
} 
la formación universitaria de un familiar ${ }^{58}$ que, al adquirir conocimientos más específicos, está contribuyendo al progreso de la actividad misma. ${ }^{59}$

El estatuto del familiar se regula tanto desde un perfil interno como externo a las relaciones con los demás miembros del grupo. $\mathrm{Y}$ aunque la normativa italiana prescinde del requisito de cohabitación, sí delimita expresamente el grado de parentesco por el cual se podrá formar parte de la empresa familiar: cónyuge, conviviente (a tenor del art. 230 ter Codice Civile), los parientes dentro del tercer grado (en línea recta: padres, hijos, abuelos, nietos y pro nietos, en línea colateral: tíos, hermanos, sobrinos) y los afines dentro del segundo (suegros, nueras, cuñados), pudiendo participar también los menores y los interdictos.

Desde una perspectiva interna, la contribución del familiar tiene un carácter amplio, ya que sólo es relevante que haya un aporte del grupo a una actividad empresarial, a su bien común y que la actividad que se desarrolla no pueda calificarse de laboral. ${ }^{60}$ Esto se aleja claramente del modelo chileno que, al no institucionalizarla, permite la contratación de un familiar aunque el Código de Trabajo no lo exprese claramente. Así, la Dirección del Trabajo ha afirmado que no hay impedimento jurídico para que exista una relación de carácter laboral entre cónyuges casados bajo el régimen de separación de bienes, participación en los gananciales ${ }^{61} \mathrm{o}$, incluso, de sociedad conyugal, ${ }^{62}$ en el caso de una empresa individual de responsabilidad limitada. ${ }^{63}$ En este último caso, la mujer casada bajo este régimen puede suscribir válidamente un contrato de trabajo con su marido en calidad de empleador, porque la empresa

\footnotetext{
${ }^{58} \mathrm{Como} \mathrm{el} \mathrm{cónyuge} \mathrm{que} \mathrm{estudia} \mathrm{medicina} \mathrm{cuando} \mathrm{la} \mathrm{empresa} \mathrm{familiar} \mathrm{es} \mathrm{una} \mathrm{farmacia:} \mathrm{Cassazione} \mathrm{Civile,}$ sec. Lav. n 901, de 27 de enero de 2000, en Diritto \& Giustizia, 2000, nº 5, p. 18

${ }^{59}$ En relación con el trabajo doméstico que desarrolla la persona que se queda en el hogar, la jurisprudencia italiana ha considerado que no necesariamente puede considerarse un aporte relativo a la empresa familiar. Y lo será solo si se encuentra indirectamente relacionado: Cassazione Civile, sec. unite, $\mathrm{n}^{\circ} 89,4$ de enero de 1995, en Nuova giurisprudenza civile e commentata, 1995, I, 1037; Cassazione Civile, sec. Lav. $\mathrm{n}^{\circ}$ 9025, 22 de agosto de 1991, en Rivista giuridica del lavoro, 1992, II, p. 474; y en Giurisprudenza italiana, 1992, I, 1.

${ }^{60}$ No sería así todas las veces que las partes han decidido acudir a otra forma societaria.

${ }^{61}$ Véase Ord. D.T. $n^{\circ}$ 0393-03, de 24 de enero de 2006.

${ }^{62}$ Sobre un análisis relativo al ordenamiento español véase: FerRANTE, Alfredo, "La empresa familiar creada por los cónyuges en régimen de sociedad de gananciales el derecho español. Perplejidades y necesidad de armonización del derecho civil y laboral", Revista Crítica de Derecho Inmobiliario, n. 704, 2007, p. 2559 y ss.
}

${ }^{63}$ Dictamen D.T. $n^{\circ}$ 4355-49, 11 de noviembre de 2013; v. también Dictámenes D.T. n ${ }^{\circ} 8134-165$ de 18 de noviembre de 1988, y Dictamen D.T. n $114-15$, de 9 de enero de 1988. 
individual tiene una personalidad jurídica y un patrimonio independiente. ${ }^{64}$ Ahora bien, esta relación subordinada, permite -y obliga a- descartar que dicho familiar tenga capacidades decisionales dentro de ella.

Frente a este sistema que se rige bajo el estatuto laboral normal $-\mathrm{y}$ que prescinde por ello del vínculo familiar y de las intrínsecas connotaciones de sus miembros- se propone otro que, como el italiano, se ciñe al estatuto propio de la empresa familiar. En este segundo, se dará relevancia a esa affectionis vel benevolentiae causa que mueve sus relaciones. A cambio, el miembro que coopere con la empresa se beneficiará de determinados derechos que trascienden lo laboral, aunque tengan carácter patrimonial. Se le concederá no sólo un derecho de mantenimiento, sino uno de reparto de ganancias en proporción a la colaboración prestada. ${ }^{65}$ Esto permite, por lo tanto, delinear desde el perfil endofamiliar un estatuto de derecho, tutelando a quien aporte continuamente, no sólo con una garantía irrenunciable sobre una pensión alimenticia suis generis, sino que también con participaciones patrimoniales que debería cuantificarse de acuerdo con la cantidad y calidad de la contribución. ${ }^{66}$

Desde un perfil externo, es decir, en cuanto a la relación entre la empresa con terceros y su actividad de gestión, la normativa italiana garantiza al familiar su derecho a voto cada vez que se requiera una actividad de administración extraordinaria, como podría ser un determinado proceso productivo o la cesación de la empresa. Se perfila así una sociedad unipersonal con estructura plurisubjetiva interna (diferente de las sociedades personalistas y por supuesto capitalistas), en la cual las actividades de ordinaria administración pertenecerían al titular, así como la responsabilidad patrimonial frente a terceros. Esta responsabilidad debería imputarse solamente a quien tiene el poder de gestión, poder que está estrechamente relacionado con la asunción de los riesgos de la misma. Sin embargo, dada la peculiaridad de esta figura, los familiares deberían poder votar mediante un mecanismo democrático, sujeto a la mayoría, en lo relativo a las decisiones empresariales de mayor relevancia. Ahora bien, los sujetos asumirían un idéntico rol y el voto no debería ser ponderado, a

\footnotetext{
${ }^{64}$ Cfr. art. 2, Ley 19.857.

${ }^{65} \mathrm{~V}$. art. 230 bis Codice Civile.

${ }^{66}$ En la experiencia italiana se ha considerado que estos beneficios se presumirían iguales y destinados no a la distribución entre los miembros, sino a la reinversión en la empresa o a la adquisición de bienes: Cassazione Civile, sec. Lav. n 11.921, de 22 de octubre de 1999, en Archivio Civile, 2000, 313 16. Sobre el punto V., v.gr., BALESTRA, Luigi, "Sulla decorrenza degli interessi sugli utili spettanti al partecipante all'impresa familiare", Famiglia e diritto, 2000, n 2, p. 128.
} 
diferencia del reparto proporcional de las ganancias, que se calcula en relación con el aporte efectuado. ${ }^{67}$

Es menester también evidenciar la solución que el ordenamiento italiano ofrece para garantizar la pervivencia de la empresa. En caso de enajenación de la participación de un familiar en ella $-\mathrm{y}$ de su consecuente retiro- o cuando se producen divisiones hereditarias por muerte del titular, los demás miembros tendrían un derecho de adquisición preferente frente a terceros.

En esta solución, especialmente para la enajenación de la cuota inter vivos, parte del presupuesto que los estados de "familiar" y "colaborador" son escindibles y por ello debe permitirse la salida a uno de sus integrantes. En la realidad chilena actual, en cambio, los familiares, al revestir en la mayoría de los casos la calidad de socios, necesitan firmar determinados protocolos para mantener el control de la sociedad que se ha constituido. Esto conduce a una regulación que sigue los patrones patrimoniales normales y que sistematizan todo tipo de relaciones entre sujetos, sin distinguir si se trata de familiares o no familiares.

\section{EL POTENCIAL REGIONAL DE LA EMPRESA FAMILIAR}

Así como en Roma el patrimonio del pater familias servía al desarrollo de su propio núcleo, transformándose luego en el pilar del comercio de mayor escala, la empresa familiar en Chile debiese considerarse como lo que en realidad es: el motor de la actividad económica de ciertos sectores o regiones en que, por sus particulares características, estructuras societarias mayores son inviables para iniciar emprendimientos.

En la determinación del entorno de lo que constituye la residencia de la familia es clave determinar una posición jurídica ad hoc para la empresa que es propedéutica no solo para constituirla, sino para tutelar los derechos de sus familiares.

La habitación familiar, por lo tanto, constituye un espacio importante no sólo desde el punto de vista físico, como aglomerado humano y social, sino también desde el punto de vista jurídico, como unión económica que se refleja en una institución que debería recibir una adecuada y más detallada regulación también bajo los perfiles del derecho civil y de familia.

\footnotetext{
${ }^{67}$ Cfr. Paladini, Mauro, "L'impresa familiare", en Bonilini, G. (director), Trattato di diritto di famiglia, Il regime patrimoniale della famiglia, UTET, Torino, 2016, T. II, pp. 1765 y ss; BALESTRA, Luigi, L'impresa familiare, Giuffré editore, Milano, 1996, p. 271. Más especificadamente v.gr. véase BALESTRA, cit. (n. 66), p. 125 y ss.
} 
En este sentido el hogar familiar se transforma en un instrumento para lograr determinadas posiciones jurídicas dentro de un contexto económico amparado por la propia Constitución, que, en su artículo primero, declara que la familia es el núcleo fundamental de la sociedad. Regular debidamente la empresa familiar en Chile es el primer paso para crear los fundamentos de una sociedad más sólida sobre todo en determinadas dimensiones territoriales o contextos geográficos.

En determinados de estos contextos núcleo familiar va a constituir la primera y en ciertas zonas, quizás la única manera de fomentar el crecimiento la economía, poe ello la empresa familiar permitirá el desarrollo económico y comercial de sectores menos favorecidos por la compleja morfología nacional.

Allá donde las grandes empresas o multinacionales no tendrían interés en invertir, la empresa familiar y la familia serán el primer y único paso para incrementar actividades que no serían apoyadas por no ser rentables desde la perspectiva de una economía de gran escala. En este sentido los contextos regionales son los primeros núcleos donde la empresa familiar debe necesariamente considerarse nuevo motor de la economía y por ello requiere una apropiada regulación que vaya más allá de aquella que limita la microempresa familiar en un contexto de casa habitación.

\section{CONCLUSIONES}

Como resultado del análisis del estado de la legislación y la interpretación que se realiza por parte de los tribunales o de la Contraloría, puede concluirse la existencia de una insuficiente regulación de la empresa familiar. En una óptica moderna, el trabajo del grupo puede funcionar fuera de los antiguos conceptos rurales y agrarios, desarrollándose en cualquier tipo de actividad económica.

La actual normativa chilena es, sin duda, escasa. No solamente omite reglamentar con acucia la microempresa familiar y los derechos y deberes de sus integrantes, sino que no considera que el contexto en el cual ésta debe desarrollarse puede limitar de facto el libre desarrollo económico que, en cambio, se garantiza por el art. 19 n. 21, 22 y 24 de la Constitución. Como se examinó, la precariedad de las normas establecidas (qué limitan la empresa familiar a un limitado contexto urbanístico), hacen que, muchas veces, sus miembros tengan que modificar la estructura societaria cuando una actividad sobrepasa un determinado punto de crecimiento, para separar y resguardar sus propios patrimonios de las contingencias que pudiere presentar el tráfico comercial y económico. 
Por otra parte, en ocasiones, la ley tampoco refl eja la realidad de estas empresas, al entender que son aquellas que se despliegan en la "casa habitación familiar", dando prevalencia a un elemento objetivo y no al subjetivo. Los problemas se evidencian en los casos en que el núcleo del hogar desarrolle la actividad fuera de dicho recinto, por necesidades de mayor espacio físico, salubridad, evitar la contaminación a vecinos o propender a la diversificación del giro.

En definitiva, se requiere una adecuada reglamentación de la empresa familiar que debe tener en consideración su naturaleza jurídica, la ordenación de sus relaciones personales internas y externas y el régimen de la prestación -laboral y patrimonial- del familiar que coopera con ella. Más allá de la asociación que la Ley chilena realiza entre microempresa y casa habitación, es la empresa familiar la que ahora debe ser objeto de estudio para revalorizar su potencial en la economía para poder contribuir al desarrollo de ambientes rurales en los que el coste oportunidad económico desincentiva las grandes empresas en invertir.

\section{BIBLIOGRAFÍA}

\section{A) DOCTRINA}

Andrini, Maria Claudia, VitToria, Daniela, Azienda coniugale e impresa familiare, Cedam, Padova, 1989.

Arteaga Echeverría, Ignacio, "En busca del concepto jurídico de empresa", Revista Chilena de Derecho, 2002, n. 3, pp. 603-620.

BALESTRA, Luigi, L 'impresa familiare, Giuffré, Milano, 1996.

BALESTRA, Luigi, Attività di impresa e rapporti familiari, Cedam, Padova, 2008.

Balestra, Luigi, "Sulla decorrenza degli interessi sugli utili spettanti al partecipante all'impresa familiare", Famiglia e diritto, 2000, n. 2, p. 125-129.

BARILlÁ, Giovanni Battista, "Impresa familiare e forma societaria: due modelli incompatibili”, Nuova giurisprudenza civile e commentata, 2015, $\mathrm{n}^{\circ} 4$, p. I, pp. 350-360.

BARRIA PAREDEs, Manuel, "La empresa familiar o explotación agropecuaria: mecanismos que permitan su continuidad a la muerte de su titular a la luz del derecho sucesorio chileno", Revista Chilena de Derecho Privado, 2018, n 31 , en prensa.

Bona, Carlo, "L'art. 230 bis C.C. e la partecipazione del familiare ad una 
società", Foro Italiano, 2015, Vol. 140, I, pp. 102-107.

Busnelli, Francesco Donato, "Impresa familiare e aziende gestite da entrambi i coniugi", Rivista trimestrale di diritto e procedura civile, 1977, pp. 1397-1411.

Consi, Francesco, "Impresa in famiglia, impresa familiare e società", Giurisprudenza commerciale, 2015, n 3, II, p. 522-530.

FERRANTE, Alfredo, “Aportaciones comparativas para la definición jurídica de un instituto: la empresa familiar en Italia", Revista de Derecho de Sociedades, 2004, n. 23, p. 465-484.

Ferrante, Alfredo, "El trabajo familiar en el Derecho español: el trabajo ¿autónomo? de sus miembros entre las mallas laborales y civiles", Estudios Financieros. Revista de trabajo y seguridad social Comentarios, casos prácticos: recursos humanos, 2007, $\mathrm{n}^{\circ}$ 292, pp. 61-112.

FERRANTE, Alfredo, "La empresa familiar creada por los cónyuges en régimen de sociedad de gananciales el derecho español. Perplejidades y necesidad de armonización del derecho civil y laboral", Revista Crítica de Derecho Inmobiliario, 2007, n 704, pp. 2559-2584.

Franceschelli, Vincenzo, "Comunione tacita familiare", Digesto Civile, III, Utet, Milano, 1988, ad vocem.

Fuenzalida Puelma, Sergio, "Concepto jurídico de empresa y su relación con otras fi guras del derecho", Revista de Derecho y Jurisprudencia, 1967, T. LXIV (3), pp. 43-53.

Ghidin, Mario, L’impresa familiare. Cedam, Padova, 1977.

GHIDONI, Luca, "Unione civile e impresa familiare: la disarmonia di una mera estensione normativa", Famiglia e Diritto, 2017, n' 7, pp. 701-705.

Invi-Fau (eds.), Bienestar Habitacional: Guía de Diseño para un Hábitat Residencial Sustentable, INVI-FAU Universidad de Chile, Santiago, 2004, disponible en línea: http://www.arqenergia.cl/images/pdf/Bienestar\%20 Habitacional.pdf, 19 de abril de 2018.

IRTI, Natalino, "L'ambigua logica dell'impresa familiare", Rivista di diritto agrario, 1980, pp. 524 ss.

OBERTo, Giacomo, "Ancora sulla pretesa gratuità delle prestazione lavorative subordinate rese dal convivente more uxorio", Famiglia e Diritto, 2016, n², pp. 132-151.

Paladin, Mauro, "L'impresa familiare", en Bonilini, G. (dir.), Trattato di diritto di famiglia. II: Il regime patrimoniale della famiglia, UTET, Torino, 2016, pp. 1737-1782.

Palavecino, Claudio, "El concepto de empresa y su problemática", Revista Laboral Chilena, 2008, n 168, pp. 80-85. 
Pannuccio, Vincenzo, "Impresa Familiare", Enciclopedia del diritto, Giuffre, Milano, 2000, ad vocem.

Prosperi, Francesco, L'impresa Familiare, Giuffrè, Milano, 2006.

ScotTI, Anna, "Dalla Corte di Cassazione un'occasione er tornare a riflettere sulla compatibilità tra impresa familiare e forme collettive di impresa", Corriere Giuridico, 2015, n 10, pp. 1249-1261.

SGP-Fosis (eds.), Definición de estándares técnico-constructivos para dar solución a las condiciones mínimas del programa habitabilidad Chile Solidario, MIDEPLAN, Santiago, 2011, documento en archivo .pdf, disponible en línea: http://sigec.mideplan.cl/sigec/docs/2620/est_ndares\%20tecnicos.pdf, 19 de abril de 2018.

Ugarte Cataldo, José Luís, "El concepto legal de empresa y el derecho laboral: cómo salir del laberinto", Revista Chilena de Derecho Privado, 2013, $\mathrm{n}^{\circ} 20$, pp. 185-213.

VIGnol, Giulio, "Comunione tacita familiare", Enciclopedia Giuridica, VII, Treccani, Roma, 1988, ad vocem.

\section{B) JURISPRUDENCIA CITADA}

\section{CHILE}

Juzgado de Letras de Casablanca, 13 de diciembre de 2011, Rol n 12657 2010

Corte de Apelaciones de Valparaíso, 7 de abril de 2006, Rol n 881-2016. Corte de Apelaciones de Temuco, 26 de julio de 2007, Rol n 419-2007. 2010.

Corte de Apelaciones de Santiago, 31 diciembre de 2010, Rol n 6591-

Corte de Apelaciones de Antofagasta, 15 febrero de 2012, Rol n ${ }^{\circ} 200-$ 2012, Id. VLex: VLEX-380192510. 2012.

Corte de Apelaciones de Valparaíso, 11 de octubre de 2012, Rol n 671 -

Corte de Apelaciones de San Miguel, 22 de abril de 2013, Rol. $\mathrm{n}^{\circ}$ 562013, Id. VLex: VLEX-586506374.

Corte de Apelaciones de Valdivia, 3 de diciembre de 2014, Rol n 318 $-2014$.

Corte de Apelaciones de Santiago, de 10 de abril de 2015, Rol n 7892 -2014 .

Corte de Apelaciones de Santiago, 9 de diciembre de 2015, Rol n ${ }^{\circ} 1552$ -2015 . 
Corte de Apelaciones de Temuco, 21 de octubre de 2016, Rol n 54402016.

Corte Suprema, 3 de noviembre de 2016, $3^{\text {a }}$ Sala (constitucional), Rol $\mathrm{n}^{\circ}$ 41069-2016.

\section{ITALIA}

Cassazione Civile, sec. Lav. $\mathrm{n}^{\circ}$ 9025, 22 de agosto de 1991, en Rivista giuridica del lavoro, 1992, II, 474; en Giurisprudenza italiana,1992, I, 1.

Cassazione Civile, sec. unite, $\mathrm{n}^{\circ}$ 89, 4 de enero de 1995, en Nuova giurisprudenza civile e commentata, 1995, I, 1037.

Cassazione Civile, sec. Lav. n 11921, 22 de octubre de 1999, en Archivio Civile, 2000, 313, 16.

Cassazione Civile, sec. Lav. $\mathrm{n}^{\circ}$ 901, 27 de enero de 2000, en Diritto \& Giustizia, 2000, n. 5, p. 18.

Cassazione Civile, sec. Unite, $\mathrm{n}^{\circ} 23676,6$ de noviembre de 2014, en base de datos De jure.

Cassazione Civile, $\mathrm{n}^{\circ} 2472,10$ de febrero de 2017, en base de datos $D e$ jure.

C) FUENTES LEGALES

Circular SII n ${ }^{\circ} 60$ de 18 de octubre de 2002.

Circular SII n ${ }^{\circ} 27$ de 14 de mayo de 2003.

Circular SII n ${ }^{\circ} 31$ de 1 de junio de 2007.

Circular SII n ${ }^{\circ} 30$ de 1 de junio de 2007.

Circular Minvu n 302, 31 de julio de 2012.

Circular Minvu n ${ }^{\circ} 118$ (DDU 126), 9 de junio de 2003.

Circular Superintendencia de Casinos n 966 de 28 de agosto de 2012.

Codice Civile Italiano.

Código Civil Chileno.

Código de Comercio Chileno.

Decreto Ley n ${ }^{\circ} 3063$ de 1979.

Decreto Ley n 3085 de 1996.

Dictamen CG de la Municipalidad de Cerro Navia $n^{\circ} 72.208,4$ de octubre de 2016.

Dictamen CG de Municipalidad de Pucón n 44.440, 29 de septiembre de 2008.

Dictamen CGR n ${ }^{\circ}$ 51.504, 14 de noviembre de 2003.

Dictamen CGR n ${ }^{\circ} 8297,19$ de febrero de 2004. 
Dictamen CGR n ${ }^{\circ}$ 9.967, 6 de abril de 2005.

Dictamen CGR n $\mathrm{n}^{\circ}$ 24.012, 19 de mayo de 2005, Id. vLex: VLEX238908346.

Dictamen CGR n ${ }^{\circ}$ 12.985, 2 de marzo de 2011.

Dictamen CGR $n^{\circ}$ 41.523, 11 de julio 2012, Id. vLex: VLEX-406752430.

Dictamen CGR n ${ }^{\circ} 33.433,30$ de mayo 2013.

Dictamen CGR n ${ }^{\circ} 11.725,17$ de febrero de 2014.

Dictamen D.T. $n^{\circ} 114 / 15,9$ de enero de 1988.

Dictamen D.T. n ${ }^{\circ} 8134 / 165,18$ noviembre de 1988.

Dictamen D.T. $\mathrm{n}^{\circ}$ 1507/17, 5 de abril de 2011.

Dictamen D.T. $n^{\circ}$ 4355/49, 11 de noviembre de 2013.

Congreso Nacional de Chile (Editor), Historia de la Ley $n^{\circ} 20.031$, Biblioteca del Congreso Nacional, Santiago, 2015, documento en .pdf disponible en línea: https://www.leychile.cl/Navegar/scripts/obtienearchivo ?id=recursoslegales/10221.3/37606/1/HL20031.pdf.

Legge n. 76/2016, de 20 de mayo de 2016

Ley 19.749 de 2001 .

Ley 19.857 de 2003.

Ord. D.T. ${ }^{\circ}$ 0393/03, 24 de enero de 2006.

Ord. D.T. $n^{\circ} 3406 / 054,3$ de septiembre de 2014.

Ord. D.T. n ${ }^{\circ} 3750 / 0064,18$ de julio de 2016. 